\title{
Married adolescent girls in rural Assiut and Souhag: Limited choices and unfulfilled reproductive health needs
}

\author{
Nahla G. Abdel-Tawab \\ Population Council \\ Doaa Oraby \\ Population Council \\ Omaima El-Gibaly \\ Manal Darwish \\ Mirette Aziz
}

See next page for additional authors

Follow this and additional works at: https://knowledgecommons.popcouncil.org/departments_sbsr-pgy

Part of the Demography, Population, and Ecology Commons, Domestic and Intimate Partner Violence Commons, Family, Life Course, and Society Commons, International Public Health Commons, Maternal and Child Health Commons, and the Women's Health Commons How does access to this work benefit you? Let us know!

\section{Recommended Citation}

Abdel-Tawab, Nahla G., Doaa Oraby, Omaima El-Gibaly, Manal Darwish, Mirette Aziz, Amira Elgazzar, and Heba Mahmoud. 2017. "Married adolescent girls in rural Assiut and Souhag: Limited choices and unfulfilled reproductive health needs," Final report. Cairo: Population Council. 
Authors

Nahla G. Abdel-Tawab, Doaa Oraby, Omaima El-Gibaly, Manal Darwish, Mirette Aziz, Amira Elgazzar, and Heba Mahmoud

This report is available at Knowledge Commons: https://knowledgecommons.popcouncil.org/departments_sbsr-pgy/ 
Married Adolescent Girls in Rural Assiut and Souhag: Limited Choices and Unfulfilled Reproductive Health Needs

\section{Nahla Abdel-Tawab \\ Doaa Oraby}

Omaima El-Gibaly

Manal Darwish

Mirette Aziz

Amira Elgazzar

Heba Mahmoud 
The Population Council confronts critical health and development issues-from stopping the spread of HIV to improving reproductive health and ensuring that young people lead full and productive lives. Through biomedical, social science, and public health research in 50 countries, we work with our partners to deliver solutions that lead to more effective policies, programs, and technologies that improve lives around the world. Established in 1952, and headquartered in New York, the Council is a nongovernmental, nonprofit organization governed by an international board of trustees.

Population Council

One Dag Hammarskjold Plaza

New York, NY 10017

Population Council/Egypt

59 Misr-Helwan Agricultural Road, Maadi

PO Box 168, Maadi

Cairo, Egypt

11431

Tel. +20 225255968

Fax: +20 225255962

www.popcouncil.org

Suggested citation:

Abdel-Tawab, Nahla, Doaa Oraby, Omaima El-Gibaly, Manal Darwish, Mirette Aziz, Amira Elgazzar, and Heba Mahmoud. 2017. "Married Adolescent Girls in Rural Assiut and Souhag: Limited Choices and Unfulfilled Reproductive Health Needs." Final Report. Cairo: Population Council. 


\section{STUDY TEAM}

\section{Population Council Team}

Dr. Nahla Abdel-Tawab

Country Director and Principal Investigator

Dr. Doaa Oraby

Senior Reproductive Health Program Officer

Mr. Aly Rashed

Senior Researcher and Data Analyst

Ms. Gihan Hosny

Program Administration Officer

\section{Assiut University Team}

Dr. Omaima El-Gibaly

Professor of Public Health and Team Leader

Dr. Manal Darwish

Assistant Professor of Public Health

Dr. Mirette Aziz

Lecturer of Public Health

Dr. Amira Elgazzar

Lecturer of Public Health

Dr. Heba Mahmoud

Assistant Lecturer of Public Health

Mr. Mina Adel Shawky

Project Coordinator

\section{Advisory Group Members (arranged in alphabetical order):}

Dr. Hany Abdel Aleem

Dr. Ahmed Hany

Dr. Ahmed Makhlouf

Dr. Omaima Youssef

Dr. Ali Zarzour
Professor of Ob \& Gyn-Assiut University

Professor of Public Health-Assiut University ${ }^{1}$

Professor of Ob \& Gyn-Assiut University ${ }^{2}$

Head of Maternal and Child Health DepartmentAssiut Health Directorate

Professor of Public Health-Assiut University 



\section{CONTENTS}

Acknowledgments ........................................................... ii

Abbreviations and Acronyms ............................................. iii

Executive Summary ..................................................... iv

Introduction ...................................................................... 1

Study Goals and Objectives ............................................... 2

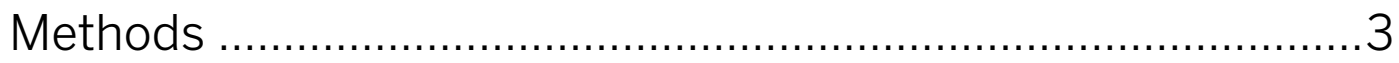

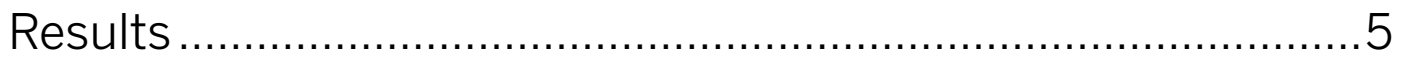

Conclusion and Recommendations ..................................... 14

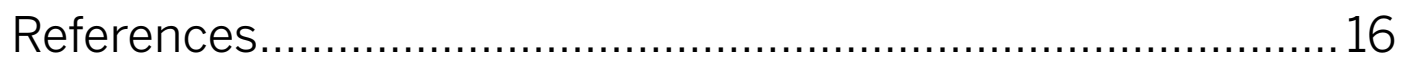




\section{ACKNOWLEDGMENTS}

We would like to express our gratitude to the Ford Foundation for supporting this study as part of a project titled "Supporting an Egyptian Academic Institution to serve as a Center of Excellence in Youth Sexual and Reproductive Health Research." The support and guidance we received from Advisory Group members and officials at Assiut and Souhag health directorates is deeply appreciated. We are also grateful to the enumerators and data collectors for making diligent efforts to identify households that included married adolescent girls and for successfully interviewing them.

Last, but not least, we extend our heartfelt thanks to the married adolescent girls who shared invaluable information on their personal experiences and reproductive health needs. It is our hope that the results of this study will lead to policies and programs that would empower married adolescent girls and eventually lead to abandonment of early marriage in Egypt. 


\section{ABBREVIATIONS AND ACRONYMS}

$\begin{array}{ll}\text { AIDS } & \text { Acquired Immunodeficiency Syndrome } \\ \text { ANC } & \text { Antenatal Care } \\ \text { CAPMAS } & \text { Central Agency for Public Mobilization and Statistics } \\ \text { COC } & \text { Combined Oral Contraceptives } \\ \text { CS } & \text { Cesarean Section } \\ \text { EDHS } & \text { Egypt Demographic and Health Survey } \\ \text { FP } & \text { Family Planning } \\ \text { HIV } & \text { Human Immunodeficiency Virus } \\ \text { IUD } & \text { Intrauterine Device } \\ \text { MAG } & \text { Married Adolescent Girl } \\ \text { MENA } & \text { Middle East and North Africa } \\ \text { MOHP } & \text { Ministry of Health and Population } \\ \text { NGO } & \text { Nongovernmental Organization } \\ \text { PHC } & \text { Primary Health Care } \\ \text { PME } & \text { Premarital Examination } \\ \text { PNC } & \text { Postnatal Care } \\ \text { RTI } & \text { Reproductive Tract Infection } \\ \text { SRH } & \text { Sexual and Reproductive Health } \\ \text { SYPE } & \text { Survey of Young People in Egypt } \\ & \end{array}$




\section{EXECUTIVE SUMMARY}

\section{Background and Objectives}

Although the median age of marriage has increased in Egypt to 21 years for women and 23 years for men and despite the presence of a law that sets the minimum age of marriage at 18 , child marriage continues to exist in Egypt. According to the Survey of Young People in Egypt (SYPE) $2014,21.1 \%$ of married female youth aged 25-29 were married before age 18 , and $33.3 \%$ of young women residing in rural Upper Egypt were reported to be married before 18. Early marriage deprives a girl of education and employment opportunities and places her at risk of early and repeat pregnancy, gender-based violence (GBV), and sexually transmitted infections (STIs). The present study examines the sexual and reproductive health ( $\mathrm{SRH}$ ) needs of married adolescent girls (MAGs) in rural Upper Egypt and identifies key contextual and cognitive factors that could mitigate or exacerbate the effects of early marriage on their sexual and reproductive health.

\section{Methodology}

The study used a cross-sectional household survey whereby MAGs (<20 years) in the select villages of Assiut and Souhag governorates were interviewed following an enumeration and listing of households in the two villages. An interviewer-administered questionnaire that inquired about social, economic, and health aspects of MAGs' lives was used. A total of 729 MAGs completed the survey (324 in Assiut and 405 in Souhag).

\section{Key Results}

More than two-thirds of interviewed MAGs were married before they turned 18 . On average the age difference between MAGs and their husbands was 7.7 years and the duration of engagement was 12.8 months. In more than half of the cases, MAGs and their husbands were blood relatives on the paternal side. Although the majority of MAGs reported accepting marriage, $41 \%$ of MAGs in Assiut and $13 \%$ of MAGs in Souhag said they had wished to delay their marriage.

The study revealed limited communication between MAGs and their husbands, especially on future plans, marital problems, desired number of children, or family planning
(FP). Likewise, MAGs had very limited decision-making power on matters related to reproductive health. Levels of exposure to gender-based violence in the past 12 months among MAGs were alarmingly high (25.9\% in Assiut and $36.4 \%$ in Souhag). Almost one in five MAGs (19.7\%) were exposed to physical or sexual violence by their husbands (27.2\% in Assiut and $13.9 \%$ in Souhag). MAGs who were exposed to GBV were unlikely to seek help, even from their own families.

MAGs showed limited knowledge of the risks associated with early marriage; warning signs during pregnancy, delivery, or the postnatal period; STIs or their symptoms; and HIV/AIDS or modes of transmission. However, their knowledge of FP methods was good, with more than 90\% able to list more than one FP method.

Despite widespread availability of free public health services in Egypt, MAGs have limited access to reproductive health information and services. The majority of MAGs did not receive a premarital exam, even though it is mandated by law. ${ }^{3}$ Their main source of information on reproductive health matters is their mother/mother-in-law, while for sexual matters about half indicated that they have no one to ask. Even though the Raeda Rifya (community health worker) who is affiliated with the rural health unit is supposed to visit all women in her catchment area to educate them about FP and other health matters, more than twothirds of MAGs in Assiut and nine out of ten in Souhag said they did not receive a visit from a Raeda Rifya. The main source of FP services listed by MAGs was the rural health unit, while for curative care services the main source of care was a private health care provider.

MAGs in rural Assiut and Souhag are exposed to a number of reproductive health risks. On average they became pregnant five months after marriage, and the average birth-spacing interval (i.e., duration between two consecutive births) was 21 months. Cesarean section rates were relatively high, reaching $41 \%$ in Assiut and 34\% in Souhag.

MAGs have high fertility desires (average of four children) and the perceived fertility desires of their husbands are even higher (average of five children). Despite high levels

\footnotetext{
${ }^{3}$ A premarital exam (PME) is supposed to include lab tests and counseling for the prospective couple about reproductive health, however both components are seldom offered.
} 
of FP knowledge among MAGs, levels of ever use and current use of FP are very low (13\% in Assiut and $8 \%$ in Souhag).

MAGs reported a number of symptoms that are indicative of gynecological disease, such as experiencing curdy white vaginal discharge, foul vaginal discharge, rash and itching around the vagina, and painful intercourse. However, their most common course of action was to "do nothing" regarding those symptoms.

A number of contextual factors have been identified that may exacerbate MAGs health vulnerability. MAGs seldom visit their families; few have close friends, and if they do they tend to see them at long intervals. Moreover, MAGs are not allowed to visit the market, health clinic, post office, or women's club alone. If they need money, they can only borrow from their husband, and very few have their own savings account.

On a more positive side, nearly half of MAGs have cell phones. Also, more than half of MAGs in Assiut and one in eight in Souhag are interested in attending educational programs.

\section{Conclusion and Recommendations}

MAGs in rural Assiut and Souhag are experiencing multiple social, economic, and health vulnerabilities. However, despite their dire situation, there are several windows of opportunity that could be capitalized on. Following is a list of policy and program recommendations that could empower MAGs, address their health needs, and ultimately eliminate child marriage.

- Primary health care services should address the needs of MAGs, as these services are available in almost every village and neighborhood in Egypt. Premarital services should include counseling on $\mathrm{SRH}$, while Raeda Rifya should be more proactive in reaching out to MAGs and referring them to the health unit.

- Programs for building adolescent girls' social, economic, and health assets should be expanded to include MAGs. Given the limited mobility of adolescent girls in rural Upper Egypt, "safe spaces" should be made available where those girls could learn and socialize.

- Community awareness activities should educate male partners about benefits of birth spacing and FP, rectify religious misconceptions about gender-based vio- lence, and encourage husband-wife communication.

- Multifaceted interventions should be adopted to stop early marriage through: (1) incentive programs to keep girls in school, (2) law enforcement to punish parents and mazoons (registrars) for drafting marriage contracts that involve underage girls, (3) livelihood opportunities for young women to enhance their status within their families, and (4) addressing socio-cultural norms that condone early marriage through mass media, educational, and religious institutions. 



\section{INTRODUCTION}

"Child marriage" is defined as marriage that occurs before the age of 18 (UNICEF 2001). During the past decade, nearly 58 million young women in developing countries married before the age of 18 (PRB 2011). Analysis of Multiple Indicator Cluster Survey data showed that one in seven adolescent girls ages 15-19 were married or in union. Rates of child marriage are highest in West and Central Africa, where around four out of ten girls marry before age 18. This is followed by Latin America and the Caribbean and the Middle East and North Africa where 24 percent and 18 percent of women ages 20 and 24 were married before age 18 (UNICEF 2017). Many factors interact to place a child at risk of marriage, including poverty, protection of girls, family honor, and the provision of stability during turbulent social and political periods (UNICEF 2011). Poor families tend to marry off their daughters early to save the cost of feeding them or sending them to school and to protect them against premarital sex or pregnancy (Amin 2011).

Child marriage is considered a violation of human rights. The right to free and full consent to a marriage that is recognized in the 1948 Universal Declaration of Human Rights and in several subsequent human rights instruments cannot be exercised when at least one partner (usually the girl) is very immature. Also, child marriage deprives a girl of other human rights such as the right to education; health; choice of who and when to marry; and a life free from violence. ${ }^{4}$ Young girls who marry early are often taken out of school; they are detached from their social network and hence enter marriage with low levels of education and limited knowledge and skills needed to negotiate adult marital roles (Mensch et al. 1998; Brady et al. 2007; UNICEF 2011). They are also prone to a number of poor health outcomes as a result of early and closely spaced pregnancies. Their low decision-making power within the family renders them unable to negotiate FP use, number and spacing of children, or use of maternal and child health services (Mensch and Greene 1998; Glynn et al. 2001; Erulkar 2013).

Furthermore, evidence suggests that early marriage is associated with elevated risk of intimate partner violence as well as sexually transmitted infections, including HIV/ AIDS, especially when girls are married to men who are more sexually experienced than themselves (Bruce 2003; Jensen and Thornton 2003; ICRW 2005; Hindin and Ansara 2008; USAID 2009; Santhya et al. 2010; Speizer and Pearson 2011).

Although median age of marriage has increased in Egypt to 21 years for women and 23 years for men, and despite the presence of a law that sets the minimum age of marriage at 18 years, child marriage continues to exist in Egypt. ${ }^{5}$ The 2014 Survey of Young People in Egypt (SYPE) revealed that $21.1 \%$ of married female youth aged $25-29$ had been married before age 18 , while $33.3 \%$ of those residing in rural Upper Egypt reported being married before age 18 (Roushdy and Sieverding 2015). The main reasons for getting girls to marry before the legal age are poverty and families' desire to protect their daughters from premarital sexual relations (El-Mouelhy 2013).

Very little is known about the situation of married adolescent girls (MAGs) in Egypt. SYPE 2014 noted that illiteracy rates were higher among young women who got married before age 18 compared to those who were married after age 18 (45.7\% versus $13.8 \%$, respectively) while the Egypt Demographic and Health Survey 2014 (EDHS 2014) showed lower levels of contraceptive use (21\% among married girls aged 15-19 compared to 42\% among those aged 20-24). The survey also revealed limited HIV-related knowledge, where $50 \%$ of those aged $15-19$ compared to $68 \%$ of those aged $20-24$ had heard of AIDS (MOHP, EIZanaty and Associates, and ICF International 2015).

The sexual and reproductive health ( $\mathrm{SRH}$ ) needs or the health-seeking behavior of Egyptian married adolescent girls (MAGs) have seldom been investigated. Hence, the current study was designed to examine the marital experiences of MAGs in Egypt and identify more precisely their sexual and reproductive health needs, their access to reproductive health information and services, as well as their health-seeking behavior. Results of the present study will contribute to designing effective interventions and programs to ameliorate the negative health effects of early marriage on MAGs and their children and eventually contribute to a decline of early marriage in Egypt.

\footnotetext{
4 "Child Marriage: A Violation of Human Rights." www.girlsnotbrides.org/wp-content/uploads/2012/10/GNB-Childmarriage-human-rights-infographic-1200px.jpg. Accessed on 13 January 2016.

${ }^{5}$ Child Law no. 126 for the year 2008 forbids issuing a marriage contract for those who are under 18 calendar years.
} 


\section{STUDY GOAL AND OBJECTIVES}

The overall goal of the current study is to further our understanding of the SRH needs of married adolescent girls in rural Upper Egypt and to assist policymakers in developing evidence-based policies and programs to assist MAGs in exercising their sexual and reproductive rights and live healthy and productive lives. The specific objectives of the study are:

1. Provide estimates of key sexual and reproductive health (SRH) indicators among married adolescent girls (MAGs) in rural Upper Egypt (e.g., contraceptive use, birth spacing, safe delivery, and sexual satisfaction);

2. Measure the extent of MAGs' exposure to various forms of intimate partner violence, including sexual violence;

3. Identify key contextual, attitudinal, and cognitive factors that could mitigate or exacerbate the effects of early marriage on girls' sexual and reproductive health;

4. Provide policy recommendations and identify opportunities for interventions and programs to empower MAGs and improve their sexual and reproductive health. 


\section{METHODS}

The current study was implemented by the Public Health and Community Medicine Department in Assiut University with technical assistance from the Population Council/ Egypt and funding from the Ford Foundation, as a part of a larger project that aimed at establishing a center of excellence in youth SRH at Assiut University. The study protocol and data collection instruments were reviewed and approved by the Research Ethics Committee at Assiut University, Central Agency for Public Mobilization and Statistics (CAPMAS), and the Population Council Institutional Review Board.

\section{Study Design}

The study used a cross-sectional household survey whereby married adolescent girls in selected villages in Assiut and Souhag were interviewed using an interviewer-administered questionnaire. The questionnaire inquired about their living conditions, marital and reproductive history, health-seeking behavior, husband-wife communication and sexual relationship, FP knowledge and use, domestic violence, and involvement in household decision-making. The questionnaire was developed through a collaborative process between the Community Medicine Department at Assiut University and the Population Council. Field training of data collectors involved pilot testing of the questionnaire among 20 MAGs in two villages that were not included in the study.

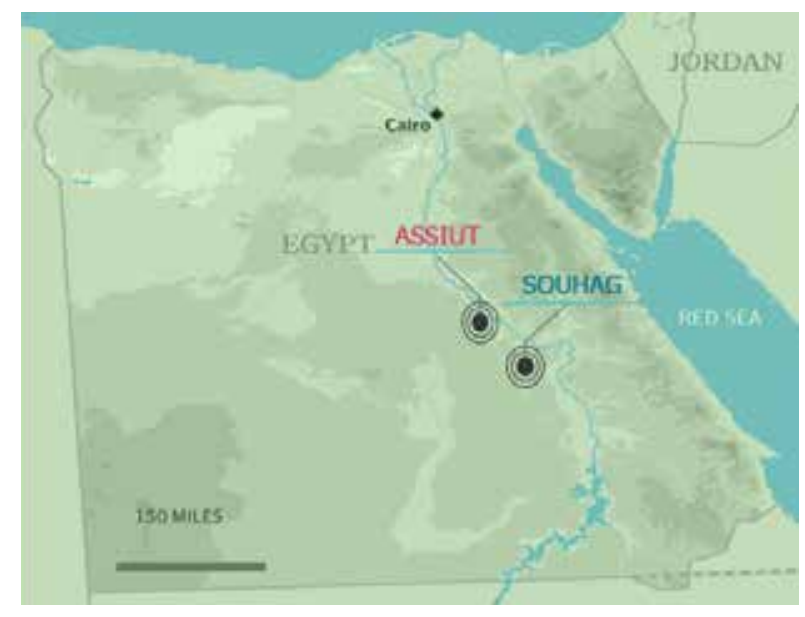

\section{Study Sites}

The study was conducted in Assiut and Souhag governorates, which are two of the poorest and most conservative governorates in Egypt (CAPMAS 2014).

Assiut Governorate is located 199 miles south of Cairo and has a population of about 4.5 million, of whom $60 \%$ live under the poverty line. Souhag Governorate is located 244 miles south of Cairo and has a total population of about 4.9 million of whom $55 \%$ live under the poverty line (CAPMAS 2014; UNDP 2010).

Within the above two governorates, the study was conducted in 23 villages and satellites that were nominated by senior officials at the two health directorates, based on reports of high incidence of early marriage. Districts selected for the study were El Badary, El Fath, Assiut, and El Quosia in Assiut Governorate, and Dar El Salam and El Monshaat in Souhag Governorate.

\section{Study Sample}

The target group was married adolescent girls (under 20 years) who had consummated their marriage and who had been married for at least three months at the time of data collection. We initially aimed to interview a total of 1,000 MAGs (i.e., 500 per governorate). However, due to difficulties in reaching the target number of respondents (described below) we ended up with a sample of 729 MAGs (324 in Assiut and 405 in Souhag). The initial plan was to enumerate all households in a randomly selected quadrant of a selected village, to list all married men and women who live in those households, and to select at random the desired number of households that have at least one MAG. However, because of difficulties in reaching the target number of MAGs, the study team decided to include all MAGs who had been identified.

\section{Data Collection Procedures}

The data collection team in each of the two governorates was composed of five trained female interviewers and one female field supervisor. The interviewer met the head of the household, explained the study to him/her, and asked for their permission to interview the listed MAG. The interviewer then explained the study to the MAG and asked for 
her informed consent before conducting the structured interview. If the head of household or the MAG refused to participate or if the MAG was not present after three call-back visits on three consecutive days, the household was dropped. In Assiut, 3 MAGs refused to participate and 11 were said not to be present during the three call-back visits, while none refused in Souhag. Interviews with MAGs lasted for about one hour each. Procedures for protection of participants' privacy and confidentiality of data were observed. Data collection was completed in three months (April to June 2015).

\section{Challenges in Data Collection}

The initial design was to include a sample of 1,000 MAGs from Assiut and Souhag. However, the study team was faced with difficulties in identifying eligible MAGs as many families denied the presence of MAGs during the listing process. To overcome this challenge, the enumeration and listing team members were escorted by female outreach workers from the local communities to establish rapport with the families and to allay their concerns. Additionally, 40 households that had indicated having a MAG during mapping and listing denied having one during data collection, hence those households were taken out of the sample.

Moreover, a few husbands/mothers-in-law, especially in Souhag were suspicious of the purpose of the survey and tried to attend the interview or asked the interviewer to share results of the interview. The interviewers were trained in how to handle such requests. In instances where privacy could not be guaranteed, the field supervisor was invited to "interview" the husband/mother-in-law outside the room where the MAG was being interviewed. The interview with husband/mother-in-law involved a subset of questions from the MAG questionnaire related to SRH knowledge. Additionally, the interviewer provided guidance to MAG respondents on how to handle questions from husbands/in-laws after the interview ended. 


\section{Socioeconomic and Demographic}

\section{Characteristics and Living Conditions of}

\section{Married Adolescent Girls (MAGs)}

The total number of interviewed MAGs who were below the age of 20 and had been married for at least three months was 729 (324 in Assiut and 405 in Souhag). Table 1 shows sociodemographic characteristics of interviewed MAGs and their husbands in the two study governorates.

Table 1. Socioeconomic and demographic characteristics of interviewed Married Adolescent Girls (MAGs) and their husbands in Assiut and Souhag Governorates

\begin{tabular}{|l|l|l|l|}
\hline & $\begin{array}{l}\text { Assiut } \\
(\mathbf{N}=324)\end{array}$ & $\begin{array}{l}\text { Souhag } \\
(\mathbf{N}=\mathbf{4 0 5})\end{array}$ & $\begin{array}{l}\text { Total } \\
\mathbf{( N = 7 2 9 )}\end{array}$ \\
\hline Age of MAGs (mean) & 18.3 & 18.5 & 18.4 \\
\hline Age of husband (mean) & 26.5 & 25.8 & 26.1 \\
\hline $\begin{array}{l}\text { Spousal age difference } \\
\text { (mean) }\end{array}$ & 8.2 & 7.3 & 7.7 \\
\hline Education of MAGs (\%) & & & $23.4 \%$ \\
\hline Did not enter school & $10.5 \%$ & $34.1 \%$ & $22.5 \%$ \\
\hline Completed primary & $23.5 \%$ & $21.7 \%$ & $34.0 \%$ \\
\hline Completed preparatory & $37.4 \%$ & $31.4 \%$ & $19.3 \%$ \\
\hline $\begin{array}{l}\text { Completed secondary/ } \\
\text { technical school }\end{array}$ & $28.1 \%$ & $12.4 \%$ & $0.9 \%$ \\
\hline $\begin{array}{l}\text { Above secondary } \\
\text { education }\end{array}$ & $0.6 \%$ & $1.0 \%$ & $10.3 \%$ \\
\hline Education of husbands $(\%)$ & & & $15.0 \%$ \\
\hline Did not enter school & $9.0 \%$ & $19.8 \%$ & $9.2 \%$ \\
\hline Completed primary & $9.9 \%$ & $8.7 \%$ & $12.9 \%$ \\
\hline Completed preparatory & $8.0 \%$ & $12.4 \%$ & $54.8 \%$ \\
\hline $\begin{array}{l}\text { Completed secondary/ } \\
\text { technical school }\end{array}$ & $65.4 \%$ & $46.3 \%$ & \\
\hline $\begin{array}{l}\text { Above secondary } \\
\text { education }\end{array}$ & $7.7 \%$ & 10.9 & \\
\hline
\end{tabular}

On average, interviewed MAGs were 18 years old, however about one-quarter were below 18 . Souhag participants included one who was aged 13 , six aged 14 , and nine aged 15, while Assiut MAGs included 12 who were 15 years old. The husbands' mean age was 27 years in Assiut and 26 years in Souhag. The average age difference between the husband and wife was seven to eight years. However, an age difference of more than 20 years was observed among three MAGs in Assiut and four in Souhag.

Educational attainment of MAGs in Souhag was generally lower than in Assiut, with 20\% being illiterate in Souhag compared to $6.5 \%$ in Assiut. On the other hand, 28\% completed secondary education in Assiut compared to $12 \%$ in Souhag. Husbands' educational level was generally higher than that of their spouses, with $65 \%$ of husbands in Assiut and 46\% in Souhag completing secondary education. Almost all interviewed MAGs were not working for cash (98.5\% in Assiut and 99.5\% in Souhag).

The majority of interviewed MAGs lived in an extended family setting with their husband's family (84\% in Assiut and $92 \%$ in Souhag). Almost all the households had electricity and nine out of ten households had a television and a satellite dish. Most of the interviewed MAGs had a private bathroom (71\% in Assiut and 63\% in Souhag), a private kitchen (71\% in Assiut and 54\% in Souhag), while few had a private eating space for themselves, their husbands, and children (7\% in Assiut and 1\% in Souhag).

\section{Getting Married}

Article 16.1 of the 1979 Convention on the Elimination of All Forms of Discrimination against Women prescribes equally for men and women: (a) The same right to enter into marriage; (b) The same right to freely choose a spouse and to enter into marriage only with their free and full consent.

Table 2 and Figure 1 show that more than two-thirds of interviewed MAGs (71.9\% in Assiut and 70.4\% in Souhag) were married before their 18th birthday. It is noteworthy that $1.2 \%$ and $4.4 \%$ of MAGs in Assiut and Souhag respectively were married as early as 12 or 13 years. The mean age at marriage among MAGs was 16.7 years in Assiut and 16.5 years in Souhag. In more than half of the cases, MAGs and their husbands were blood relatives on the father's side (59\% in Assiut and 67\% in Souhag). The majority of MAGs were introduced to their husbands through relatives, friends, or neighbors (88\% in Assiut and 92\% in Souhag), while the remainder were either neighbors or knew each other while studying. Over $90 \%$ of interviewed 
Table 2. Marriage characteristics of Married Adolescent Girls

\begin{tabular}{|l|l|l|}
\hline & Assiut & Souhag \\
\hline Age at marriage (mean) & 16.7 & 16.5 \\
\hline Married before age 18 (\%) & 71.9 & 70.4 \\
\hline $\begin{array}{l}\text { Duration of engagement (mean) } \\
\text { (in months) }\end{array}$ & 13.6 & 12.4 \\
\hline $\begin{array}{l}\text { MAGs who had opportunity to } \\
\text { know prospective husband well } \\
(\%)\end{array}$ & 71.9 & 53.2 \\
\hline $\begin{array}{l}\text { MAG and husband were blood } \\
\text { relatives (\%) }\end{array}$ & 58.9 & 67.1 \\
\hline $\begin{array}{l}\text { MAGs who wished to delay } \\
\text { marriage (\%) }\end{array}$ & 41.2 & 12.9 \\
\hline
\end{tabular}

Figure 1. Married Adolescent Girls who were married before their 18th birthday

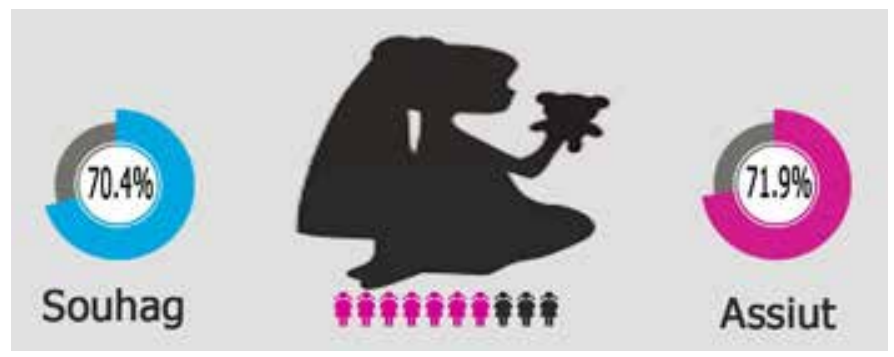

MAGs reported that their families "sought their opinion" regarding the groom and sought their "consent" before marriage. Although the majority of MAGs reported approving the marriage (86\% in Assiut and $97 \%$ in Souhag), a sizable proportion of respondents in Assiut and to a lesser extent in Souhag indicated that they had wished to delay their marriage (41\% in Assiut and 13\% in Souhag).

The average duration of engagement was almost one year (13.6 months in Assiut and 12.4 months in Souhag). However, a few MAGs (7\%) indicated that they got married immediately with no engagement period. During their engagement period, more MAGs in Assiut than Souhag indicated that they were able to know their prospective husband well ( $72 \%$ versus $53 \%$, respectively) and to discuss future plans (68\% versus 59\%, respectively). On average, MAGs' parents received a mahr (dowry) of EGP 4,498 and a shabka (jewelry) worth EGP 11,368. ${ }^{6}$

In Egypt, a marriage contract is issued by a mazoon (a registrar), who then registers the marriage in court, provided that both the bride and the groom are above the legal age
Table 3. Percent of Married Adolescent Girls who discuss selected topics on a regular basis with their husbands

\begin{tabular}{|l|l|l|}
\hline Topic & $\begin{array}{l}\text { Assiut } \\
(\mathbf{N = 3 2 4 )}\end{array}$ & $\begin{array}{l}\text { Souhag } \\
(\mathbf{N}=405)\end{array}$ \\
\hline Household finances & $58.6 \%$ & $33.7 \%$ \\
\hline Wife's health & $64.0 \%$ & $74.0 \%$ \\
\hline Sexual relationship & $66.5 \%$ & $44.2 \%$ \\
\hline Desired number of children & $42.0 \%$ & $27.0 \%$ \\
\hline Children's health & $41.0 \%$ & $42.0 \%$ \\
\hline Future plans & $35.5 \%$ & $15.2 \%$ \\
\hline Marital problems & $27.6 \%$ & $18.6 \%$ \\
\hline Family planning & $10.2 \%$ & $1.7 \%$ \\
\hline
\end{tabular}

(18 years). Even though $71.2 \%$ of interviewed MAGs got married before the legal age, nearly half were married in the presence of a mazoon ${ }^{7}$ (57\% in Assiut and 53\% in Souhag). To ensure a marriage is registered after the girl turns 18, MAGs' families received guarantees from the groom $(61.7 \%$ and $60.2 \%$ in Assiut and Souhag, respectively). Those guarantees were in the form of checks or trust receipts.

\section{Husband-Wife Relationships \\ Communication and Decision-making}

Husband-wife communication is essential for creating mutual understanding between spouses and subsequently a satisfactory marital relationship. MAGs were asked about the frequency of discussing certain topics with their husbands.

Table 3 shows that frequently discussed topics were health of the wife (64\% in Assiut and $74 \%$ in Souhag) and their sexual relationship (66.5\% in Assiut and 44.2\% in Souhag). FP ranked last among topics discussed on a regular basis between spouses, with nearly $2 \%$ of MAGs in Souhag reporting discussing it on a regular basis with their husbands, and 10\% in Assiut. It is noteworthy that apart from discussing the wife's and children's health, MAGs in Souhag were less likely to have regular discussions with their husbands compared to those in Assiut.

MAGs' ability to take part in household decisions is an indication of their autonomy and control over their lives. MAGs were asked to report on who had the final say on a list of topics, namely wife's health care, FP, desired number of children, and timing of pregnancy. Table 4 shows that

\footnotetext{
${ }^{6}$ US $\$ 1.00=18$ EGP.

7 For MAGs who were married before the legal age, the mazoon drafts a marriage contract but does not register it in court until the girl reaches legal age.
} 
Table 4. Percent of Married Adolescent Girls who had the final say on selected reproductive health topics

\begin{tabular}{|l|l|l|}
\hline Topic & $\begin{array}{l}\text { Assiut } \\
(\mathrm{N}=324)\end{array}$ & $\begin{array}{l}\text { Souhag } \\
(\mathrm{N}=405)\end{array}$ \\
\hline Wife's health care & $20.7 \%$ & $5.4 \%$ \\
\hline Desired number of children & $4.3 \%$ & $0.5 \%$ \\
\hline Timing of pregnancy & $13.6 \%$ & $0.2 \%$ \\
\hline Family planning & $17.3 \%$ & $0.7 \%$ \\
\hline
\end{tabular}

in general MAGs had limited decision-making power on matters related to reproductive health. However, those in Assiut consistently had more decision-making power than those in Souhag on matters related to their own reproductive health.

\section{Sexual Relationship}

The wedding night bears a great significance for MAGs as it almost invariably represents their first sexual encounter. On mode of defloration, $98 \%$ of participants indicated that it was through sexual relationship with the husband (as opposed to manual defloration by a traditional birth attendant). Nearly one-third of MAGs stated that they faced problems on their wedding night (31\% in Assiut and 25.9\% in Souhag), with fear being the most frequently mentioned problem.

The study measured sexual satisfaction among MAGs using a five-point scale (highly satisfied, satisfied, not sure, dissatisfied, strongly dissatisfied). The majority of MAGs indicated that they were satisfied (55.5\% in Assiut and $66.2 \%$ in Souhag) or highly satisfied (37.1\% in Assiut and $31.6 \%$ in Souhag) with the sexual relationship with their spouses. The above result should be interpreted with caution as one-quarter of those MAGs were below age 18 and hence from a legal and human rights perspective they are not having consensual sex.

Figure 2. Married Adolescent Girls exposed to gender-based violence

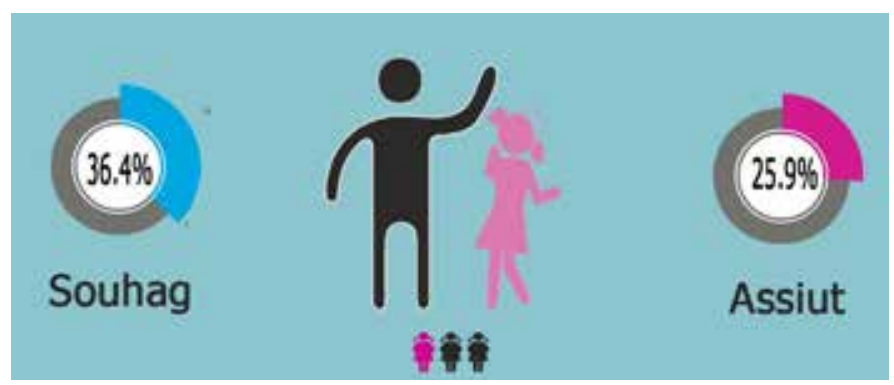

Gender-Based Violence

Gender-based violence was explored using a set of questions inquiring about physical, sexual, and emotional abuse, and violence during pregnancy. Out of the total sample nearly one-third (31.7\%) reported being exposed to some form of physical, emotional, or sexual abuse by their husband in the last 12 months (36.4\% in Souhag versus 25.9\% in Assiut) (see Figure 2). Exposure to physical violence (i.e., being beaten, slapped on the face, or pushed) was reported by more MAGs in Assiut (21.1\%) than in Souhag (10.6\%). Physical or sexual violence by the husband was reported by $19.7 \%$ of MAGs (27.2\% in Assiut and $13.9 \%$ in Souhag). These rates are slightly higher than those reported by 15-19-year-old married women at EDHS 2014 (16.5\%) (MOHP, El-Zanaty and Associates, and ICF International 2015).

As to sexual violence, nonconsensual sex in the last 12 months was reported by $19.8 \%$ of MAGs in Assiut and $8.4 \%$ in Souhag (as opposed to 5.5\% among 15-19-yearold women in EDHS 2014). Being forced to have sex while the husband was high or drunk was reported by $5.9 \%$ in Assiut and $0.2 \%$ in Souhag, while being forced to do sexual acts against their will was reported by $11.1 \%$ of MAGs in Assiut and 5.2\% of MAGs in Souhag. Slightly more MAGs in Assiut than Souhag reported exposure to some form of violence during pregnancy ( $8.7 \%$ in Assiut and $4.7 \%$ in Souhag).

MAGs who were exposed to any form of violence were asked if they sought help or talked with someone about it. Substantially more MAGs in Souhag than in Assiut (62.7\% versus $37.8 \%$, respectively) sought help or support, mainly from the MAGs' own family. None of the interviewed MAGs mentioned seeking external support (e.g., help from an NGO or police). MAGs who did not seek help gave reasons such as "no value to doing so," "fear of husband," "violence is normal," and "do not know whom to consult."

\section{Reproductive Health of Married Adolescent Girls}

The 1994 International Conference on Population and Development (ICPD) Programme of Action (PoA) called for "meeting the educational and service needs of adolescents to enable them to deal in a positive and responsible way with their sexuality." It also stressed that reproductive health services should be made accessible through primary health care systems to individuals of all appropriate ages, including adolescents, as soon as possible and no later than the year 2015 (UN 1995). 


\section{Reproductive Health Knowledge}

The majority of interviewed MAGs were aware of the legal age of marriage (68\% in Assiut and $75 \%$ in Souhag). However, they were less likely to be aware of problems associated with early marriage. Problems most likely to be mentioned were health problems (mentioned by 36\% in Assiut and 35\% in Souhag), social problems (33\% in Assiut and 31\% in Souhag), nonregistration of the marriage (17.9\% in Assiut and 17\% in Souhag), and failure to issue a birth certificate for the newborn (11.7\% in Assiut and 5.9\% in Souhag). It is noteworthy that around half of MAGs did not list any problems related to early marriage, while almost one-fifth (17.3\% in Assiut and 23.5\% in Souhag) did not believe that early marriage was associated with any problems.

Interviewed MAGs were asked if someone had informed them before marriage about what to expect on the wedding night. Less than half (42\% in Assiut and $48.4 \%$ in Souhag) stated that someone discussed this issue with them. That person was most likely to be the mother or a female relative in both Assiut and Souhag.

Adolescent girls' reproductive health awareness regarding issues such as FP, delaying first pregnancy, birth spacing, and antenatal, natal, and postnatal care is instrumental to making sound decisions regarding reproductive health. Almost all participants were aware of FP methods (97\% in Assiut and 92\% in Souhag). Table 5 shows that most commonly listed methods were pills (87\% in Assiut and $89 \%$ in Souhag), followed by injectables (84\% in Assiut and 87\% in Souhag), IUDs (74\% in Assiut and 63\% in Souhag), then subdermal implants (26\% in both Assiut and Souhag). The

Table 5. Percent of Married Adolescent Girls who know about family planning methods and sexually transmitted infections

\begin{tabular}{|l|l|l|}
\hline & $\begin{array}{l}\text { Assiut } \\
(\mathbf{n = 3 2 4 )}\end{array}$ & $\begin{array}{l}\text { Souhag } \\
(\mathbf{n = 4 0 5})\end{array}$ \\
\hline Knows oral pills & 87.3 & 88.9 \\
\hline Knows injectables & 84.3 & 86.9 \\
\hline Knows IUD & 74.4 & 63.2 \\
\hline Knows condoms & 1.2 & 0.2 \\
\hline $\begin{array}{l}\text { Knows subdermal } \\
\text { implants }\end{array}$ & 26.0 & 26.0 \\
\hline Knows LAM & 10.1 & 0.0 \\
\hline Heard of STIs & 22.5 & 18.6 \\
\hline Heard of HIV & 34.9 & 30.0 \\
\hline
\end{tabular}

lactational amenorrhea method (LAM) was listed by one in ten MAGs in Assiut but none in Souhag. It is noteworthy that none of the interviewed MAGs were able to identify the three criteria for effective use of breastfeeding as an FP method. As for condoms, only 1.2\% in Assiut and $0.2 \%$ in Souhag identified condoms as an FP method.

When asked about the right age to become pregnant, one in ten MAGs listed an age below 18 years (9.4\% in Assiut and $11.5 \%$ in Souhag). When asked about the most appropriate time of the menstrual cycle to have sexual relations with the husband if a woman wants to get pregnant, nearly half of interviewed MAGs (41\% in Assiut and $47.7 \%$ in Souhag) mentioned mid-cycle as the most appropriate time.

Knowledge of danger signs during pregnancy, labor, and the postpartum period was low among study participants, as nearly half could not identify one correct danger sign during pregnancy (40.1\% in Assiut and 56.3\% in Souhag), labor (40.1\% in Assiut and 50.6\% in Souhag), or immediately postpartum (29\% in Assiut and $49.1 \%$ in Souhag).

On sexually transmitted infections (STIs), less than onefourth (22.5\% in Assiut and 18.6\% in Souhag) reported that they had ever heard of STIs. Of those who heard of an STI, the majority could not identify symptoms of STIs in males or females. However, nearly half of them stated that they would consult a physician if they suspected that their husband had an STI (56\% in Assiut and 45\% in Souhag). None of them stated that they would use a condom if they suspected that their husband had an STI.

When asked specifically about HIV/AIDS, nearly one-third of interviewed MAGs (34.9\% in Assiut and 30.0\% in Souhag) said they had heard of AIDS. Of those who had heard of AIDS, nearly half (55.7\% in Assiut and 58.6\% in Souhag) listed sexual relations with an infected person as a means of transmission and nearly one-third listed exposure to infected blood (24.7\% in Assiut and 35.5\% in Souhag). It is worth noting that transmission via shared needles was listed only by $0.02 \%$ and $0.1 \%$ of MAGs who had heard of AIDS in Assiut and Souhag, respectively. Furthermore, transmission from infected mother to child was listed by only $11.5 \%$ of MAGs who had heard of AIDS in Souhag and none in Assiut.

Access to Reproductive Health Information and Services Public primary health care services are provided free of charge in almost every village and every neighborhood in Egypt, but they are not necessarily accessible to MAGs. 
Figure 3. Main source of information on reproductive health for Married Adolescent Girls

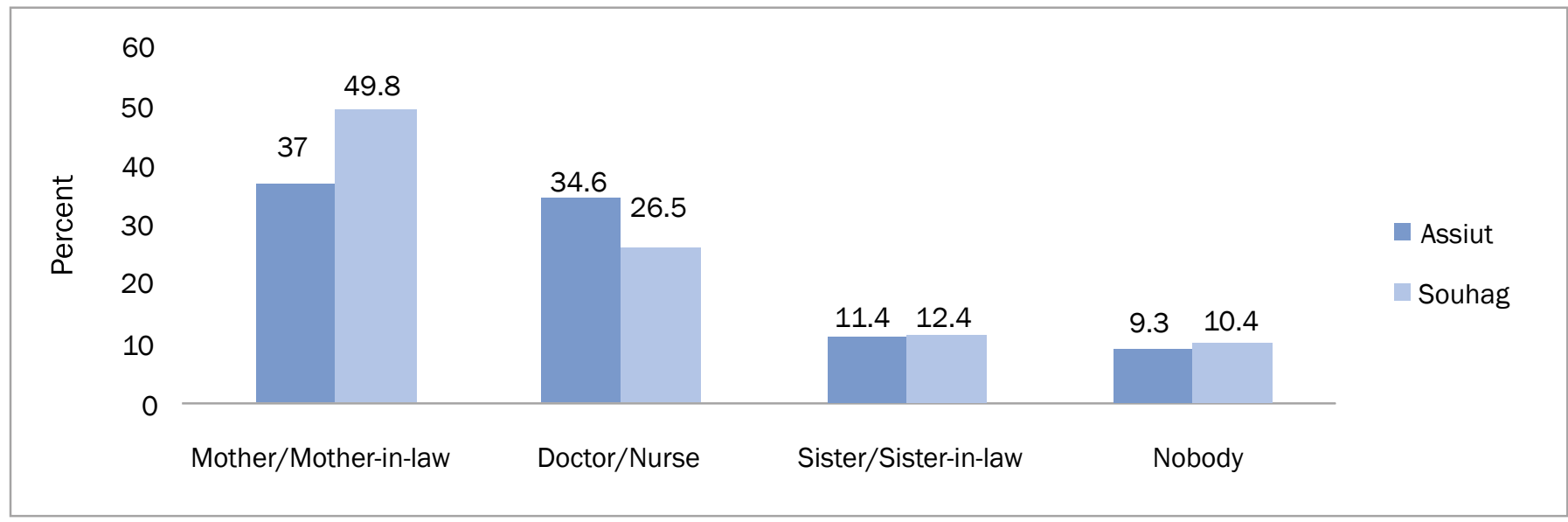

Figure 4. Main source of information on sexual health for Married Adolescent Girls

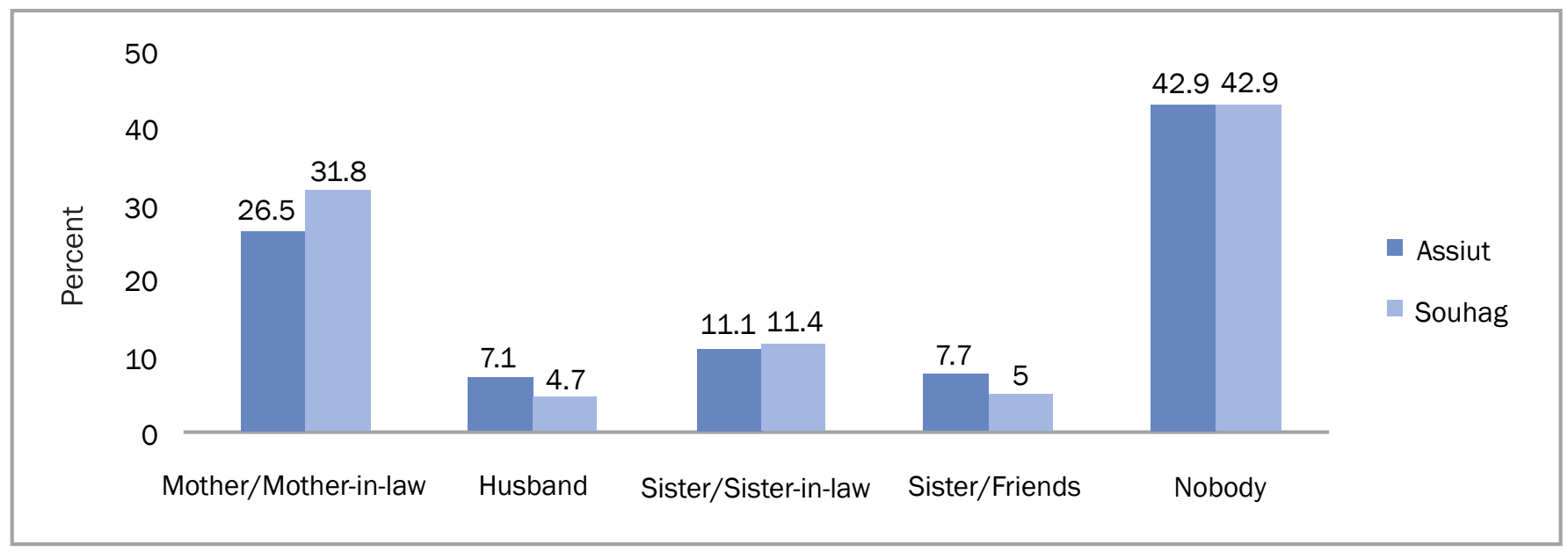

According to Law 126 of 2008 , a prerequisite for registering a marriage contract is having a certificate from a public health facility indicating that the couple has received a premarital examination (PME). Only one-third of interviewed MAGs indicated receiving a PME (31\% in Assiut and $30 \%$ in Souhag) and it was mainly composed of a medical examination and laboratory investigations, but no counseling. It is noteworthy that a large proportion of MAGs may not have received a PME because their marriage was not officially registered as they were married under the legal age.

Among MAGs who did not receive a PME, nearly half (43\% in Assiut and $42 \%$ in Souhag) said they would have liked to have received such services. Topics they wanted to be counseled on were marital relations, pregnancy and delivery, child rearing, personal hygiene, and FP.
Figure 3 shows the main sources of information on reproductive health that MAGs consult. The most commonly listed sources were mother/mother-in-law (37\% in Assiut and $50 \%$ in Souhag) followed by doctor/nurse (35\% in Assiut and 27\% in Souhag), then sister/sister-in-law (11\% in Assiut and $12 \%$ in Souhag). One-tenth of the interviewed MAGs (9\% in Assiut and 10\% in Souhag) did not mention a source of information.

On matters related to their sexual health, almost half (43\% in Assiut and Souhag) indicated that they had no one to ask while nearly one-third stated their mother/mother-inlaw (27\% in Assiut and 32\% in Souhag). It is noteworthy that none of the interviewed MAGs mentioned doctors/ nurses as a source of information on matters related to sexual health (Figure 4). 
Table 6. Percent of Married Adolescent Girls who reported that medical services are available at the village level

\begin{tabular}{|l|l|l|}
\hline & $\begin{array}{l}\text { Assiut } \\
(\mathbf{n}=\mathbf{3 2 4})\end{array}$ & $\begin{array}{l}\text { Souhag } \\
(\mathbf{n}=\mathbf{4 0 5})\end{array}$ \\
\hline $\begin{array}{l}\text { Family planning } \\
\text { services }\end{array}$ & 85.8 & 67.8 \\
\hline ANC & 17.3 & 6.9 \\
\hline Sexuality counseling & 7.1 & 1.5 \\
\hline Infertility services & 2.2 & 1.5 \\
\hline
\end{tabular}

Table 7. Childbearing behaviors among Married Adolescent Girls

\begin{tabular}{|l|l|l|}
\hline & Assiut & Souhag \\
\hline Ever pregnant (\%) & 76.2 & 67.7 \\
\hline Currently pregnant (\%) & 42.1 & 36.3 \\
\hline $\begin{array}{l}\text { Number of living children } \\
\text { (mean) }\end{array}$ & 1.1 & 1.2 \\
\hline $\begin{array}{l}\text { Mean birth-spacing } \\
\text { interval (months) }\end{array}$ & 19.3 & 22.5 \\
\hline $\begin{array}{l}\text { Mean onset of first } \\
\text { pregnancy following } \\
\text { marriage (months) }\end{array}$ & 4.1 & 5.2 \\
\hline
\end{tabular}

Nearly one-third of MAGs in Assiut and one-tenth of MAGs in Souhag (30.9\% and 9.9\%, respectively) reported receiving a visit by someone from the health unit, mostly a Raeda Rifya. ${ }^{8}$ Most commonly discussed topics were antenatal care (ANC) (45\% of MAGs who were visited by someone from the health unit) and to a lesser extent FP (39\% and $30 \%$ of MAGs who were visited by someone from the health unit in Assiut and Souhag, respectively).

On geographic access to health services, MAGs were asked about the best place that a woman can go if she needs FP services, antenatal care, counseling on sexual problems, or infertility services. Table 6 shows that FP services were mostly likely to be accessible at the village level (86\% in Assiut and 68\% in Souhag), while infertility services were least likely to be available at the village level ( $2 \%$ in Assiut and Souhag).

\section{Reproductive Health Practices}

Childbearing

Reproductive health practices of MAGs, such as early and repeated pregnancy, could pose a number of risks to their health and well-being. Table 7 shows that among
Table 8. Place of delivery of the last child among Married Adolescent Girls

\begin{tabular}{|l|l|l|l|}
\hline & $\begin{array}{l}\text { Assiut } \\
(\mathbf{N}=152)\end{array}$ & $\begin{array}{l}\text { Souhag } \\
(\mathbf{N}=\mathbf{1 9 6})\end{array}$ & $\begin{array}{l}\text { Total } \\
(\mathbf{N}=348)\end{array}$ \\
\hline & \multicolumn{3}{|c|}{ Percent } \\
\hline Home & 10.5 & 12.3 & 11.5 \\
\hline Public facility & 11.8 & 8.2 & 9.8 \\
\hline NGO health facility & 18.4 & 5.6 & 11.2 \\
\hline Private hospital & 14.5 & 4.6 & 8.9 \\
\hline Private clinic & 25.7 & 55.9 & 42.7 \\
\hline University hospital & 19.1 & 9.7 & 13.8 \\
\hline Don't know/remember & 0.0 & 3.6 & 2.0 \\
\hline
\end{tabular}

Figure 5. Married Adolescent Girls who were ever pregnant
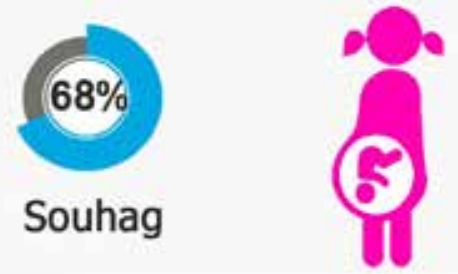

Assiut

interviewed MAGs, 76.2\% in Assiut and 67.7\% in Souhag were ever pregnant (see also Figure 5), while $42.1 \%$ in Assiut and $36.3 \%$ in Souhag were currently pregnant. On average, MAGs in Assiut and Souhag had 1.1 and 1.2 living children with a range from $0-2$ and $0-3$, respectively. On average, the first pregnancy occurred 4.6 months after getting married (with a range of 0-60 months). Fourteen percent of MAGs in Assiut said they did not want to get pregnant then, while 11 percent of MAGs in Souhag did not want to or were not sure. The average birth-spacing interval was nearly 21 months (19.3 in Assiut and 22.5 months in Souhag).

Of MAGs who ever got pregnant, more than four-fifths received ANC during their first pregnancy (84\% in Assiut and $88 \%$ in Souhag). The private sector was the main provider of ANC being reported by $84 \%$ of MAGs who received ANC in Assiut and 97\% of MAGs in Souhag. The place of last delivery was most likely to be a private clinic (25.7\% in Assiut and 55.9\% in Souhag).

MAGs who ever got pregnant were asked about the place of last delivery. As shown in Table 8, twice as many deliveries in Souhag took place in a private clinic compared to Assiut (55.9\% versus 25.7\%, respectively), while in Assiut

${ }^{8}$ Raedat Rifyat are community outreach workers who are affiliated with the Ministry of Health and Population (MOHP) and who supposedly make home visits to women in rural areas to educate them about various health topics, including family planning, nutrition, and child health. 
Figure 6. Married Adolescent Girls who delivered by C-section

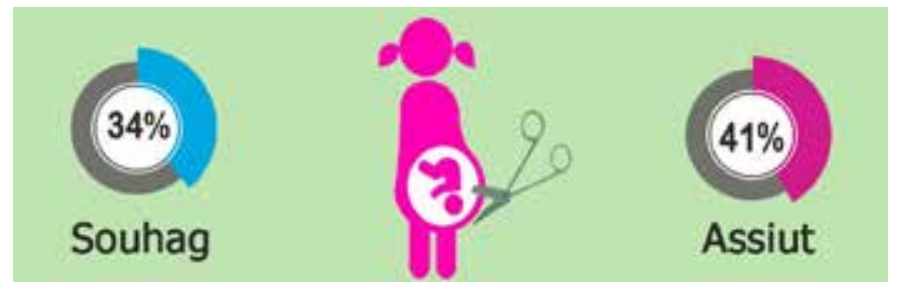

Figure 7. Married Adolescent Girls' desired number of children

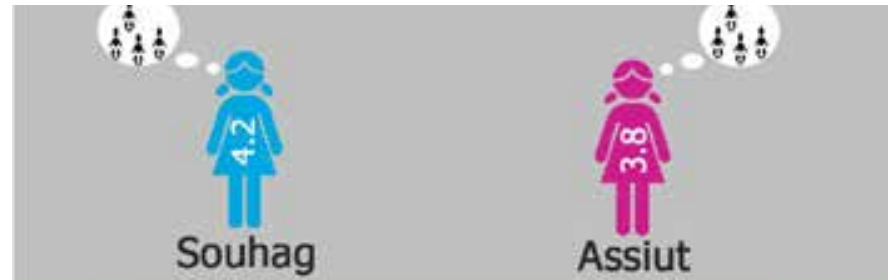

Figure 8. Married Adolescent Girls' perceptions of attitudes of husbands and mothers-in-law toward selected aspects of family planning

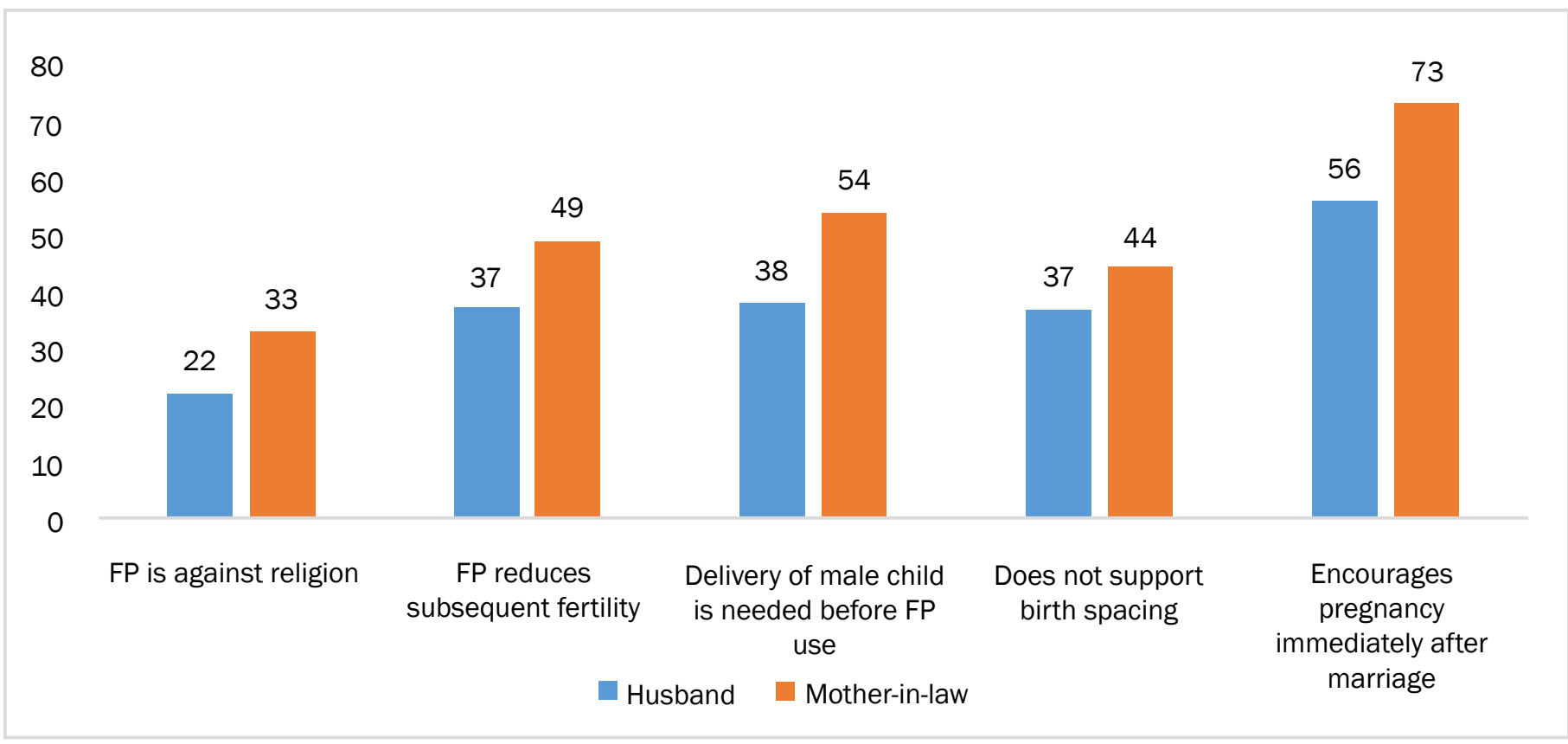

twice as many deliveries took place at a university hospital compared to Souhag ( $19.1 \%$ versus $9.7 \%$, respectively). Home deliveries accounted for roughly one in ten deliveries (10.5\% in Assiut and $12.3 \%$ in Souhag). Public facilities accounted for nearly one in ten deliveries in both Assiut and Souhag.

Cesarean section rates in the last delivery were relatively high among interviewed MAGs, reaching 41\% in Assiut and $34 \%$ in Souhag (see Figure 6). ${ }^{9}$ It is worth noting that $26 \%$ of MAGs in Assiut and 16\% of those in Souhag reported complications in their last delivery, namely bleeding or prolonged labor. Only one-quarter of MAGs reported receiving postnatal care (27\% in both Assiut and in Souhag). Again, the private sector was the main provider of postnatal care (PNC) (54\% of those who received PNC in Assiut and $84 \%$ in Souhag).
Family Planning Attitudes and Practices

On average the total desired number of children listed by MAGs was 3.8 in Assiut and 4.2 in Souhag (see Figure 7), while the number of children desired by their husbands (as reported by MAGs) was 4.7 in Assiut and 5.4 in Souhag. MAGs' perceptions of the attitudes of their husband and mother-in- law toward FP were explored using a battery of statements to which MAGs indicated on a scale of 1-5 if they strongly agree/disagree with each statement. Figure 8 shows that both husbands and mothers-in-law are perceived by MAGs to not support FP, with mothers-in-law being even less supportive than husbands.

Although as mentioned above, a great majority of interviewed MAGs were aware of FP methods (97\% in Assiut and $92 \%$ in Souhag), a small fraction ever practiced FP (13\% in Assiut and $8 \%$ in Souhag). Current use of FP was very low (8\% in Assiut and 4\% in Souhag) compared to

${ }^{9}$ WHO guidelines (2015) indicate that Cesarean section rates above 10-15 percent were not associated with improved maternal or fetal outcomes. 
Table 9. Sexual and reproductive health symptoms reported by Married Adolescent Girls ${ }^{10}$

\begin{tabular}{|c|c|c|c|}
\hline \multirow[t]{2}{*}{ SRH symptoms } & $\begin{array}{l}\text { Assiut } \\
(\mathrm{N}=324)\end{array}$ & $\begin{array}{l}\text { Souhag } \\
(N=405)\end{array}$ & $\begin{array}{l}\text { Total } \\
(\mathrm{N}=729)\end{array}$ \\
\hline & \multicolumn{3}{|c|}{ Percent } \\
\hline $\begin{array}{l}\text { Curdy white vaginal } \\
\text { discharge }\end{array}$ & 56.5 & 28.6 & 41.0 \\
\hline $\begin{array}{l}\text { Foul vaginal } \\
\text { discharge }\end{array}$ & 31.8 & 19.5 & 25.0 \\
\hline $\begin{array}{l}\text { Vaginal bleeding after } \\
\text { intercourse }\end{array}$ & 5.9 & 1.2 & 3.3 \\
\hline $\begin{array}{l}\text { Abnormal vaginal } \\
\text { bleeding }\end{array}$ & 11.4 & 3.2 & 6.9 \\
\hline $\begin{array}{l}\text { Rash and itching } \\
\text { around the vagina }\end{array}$ & 30.6 & 17.0 & 23.0 \\
\hline $\begin{array}{l}\text { Failure of arousal } \\
\text { and/or orgasm }\end{array}$ & 9.6 & 2.5 & 5.6 \\
\hline Vaginal dryness & 15.7 & 5.4 & 10.0 \\
\hline Lack of sexual desire & 13.6 & 4.0 & 8.2 \\
\hline Painful intercourse & 29.0 & 10.1 & 18.5 \\
\hline $\begin{array}{l}\text { Other gynecological } \\
\text { symptoms }\end{array}$ & 0.9 & 4.0 & 2.6 \\
\hline
\end{tabular}

the 2014 EDHS national average of $18.9 \%$ among ever-married women less than 20 years of age (Ministry of Health and Population, El-Zanaty and Associates and ICF International 2015). Of those who ever used FP, more MAGs in Assiut than in Souhag started after the birth of the first child (74\% in Assiut and 50\% in Souhag), while more MAGs in Souhag than in Assiut started after the birth of their second child (19\% in Assiut and 38\% in Souhag). Among current users, oral pills came as the first method, used by $44 \%$ of users in Assiut and $72 \%$ of users in Souhag. It is worth mentioning that the IUD was more likely to be used in Assiut than Souhag (32\% of users in Assiut and $6 \%$ in Souhag).

Among MAGs who never used FP, the main reasons were: "difficulty of getting pregnant" (24.5\%), "currently pregnant" (23.9\%), "wanting to get pregnant" (18.1\%), and "husband's opposition" (11.9\%). It is noteworthy that more participants in Souhag than in Assiut reported not using FP because they want to get pregnant (21.1\% versus $14.0 \%$, respectively) or because their husband disapproves of FP use (15.7\% versus 6.8\%, respectively).
RH-seeking behavior

MAGs were asked if they experienced any of the SRH symptoms listed in Table 9 in the past four months and how they reacted to those symptoms. Results shown in Table 9 suggest significant experience of STI symptoms among MAGs, namely curdy vaginal discharge (56.5\% in Assiut and $28.6 \%$ in Souhag), foul-smelling vaginal discharge (31.8\% in Assiut and 19.5\% in Souhag), and vaginal itching (30.6\% in Assiut and 17\% in Souhag).

More than half of MAGs who reported gynecological problems responded to those symptoms by "doing nothing," while more than four out of five MAGs who reported sexual complaints did nothing about them.

\section{Mobility, Connectedness, and Social Networks}

Results of this survey suggest that MAGs were more likely to be visited by their families than to go and visit their families themselves. About one-third and one-quarter of MAGs in Assiut and Souhag respectively (35.5\% of those in Assiut and $26 \%$ of those in Souhag) visited their family once a month, while one-quarter (22.5\% in Assiut and $24 \%$ in Souhag) visited their family on special occasions. On the other hand, one-quarter of MAGs were visited by their families once a week (26.5\% in Assiut and $23.8 \%$ in Souhag), while nearly one-third were visited once a month (28.4\% in Assiut and 31\% in Souhag).

Figure 9. Married Adolescent Girls who have no close friends

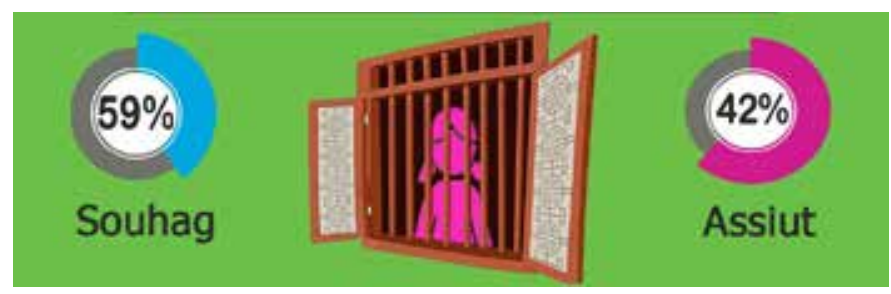

MAGs were asked about the number of close friends they have. Almost half stated they have no close friends (42\% in Assiut and 59\% in Souhag) (see Figure 9). Those who had close friends reported meeting them at long intervals (i.e., at periods longer than six months).

MAGs were asked about places they can visit alone, with someone, or not at all. Almost one-third are allowed to visit their family home alone (32\% in Assiut and 30\% in Souhag) and almost one-tenth are allowed to visit their relatives' home alone (13\% in Assiut and $8 \%$ in Souhag).

\footnotetext{
${ }^{10}$ Multiple complaints were allowed.
} 
On the other hand, almost all MAGs in either governorate were not allowed to go to the market, post office, women's club, community development association, or youth center alone. Going to the health unit or private doctor alone is allowed for a very small percentage of MAGs in Assiut (nearly 4\%) and none in Souhag.

On members of their social network from whom they could borrow money, the majority of MAGs stated their husband (87.9\% in Assiut and $86.7 \%$ in Souhag). For advice from someone she trusts regarding her relationship with her husband, the MAG's family ranked first $(43.5 \%$ in Assiut and $64.7 \%$ in Souhag) followed by her husband's family (27\% in Assiut and 24\% in Souhag). Interestingly, one-fifth of MAGs in Assiut (22\%) and one-tenth of MAGs in Souhag (8.4\%) stated that they could trust nobody.

Other indicators that were used to measure autonomy were having a mobile phone and a savings account. Nearly half of MAGs had mobile phones (63\% in Assiut and 47\% in Souhag). On the other hand, very few MAGs (3\% in Assiut and 1\% in Souhag) had a savings account.

Opportunities for Increased Social Engagement MAGs were asked if they would be interested in attending an "educational program for young women like herself" if offered in their villages. Nearly half of MAGs in Assiut (52\%) expressed interest compared to a much smaller percentage of those in Souhag (16\%). Skills MAGs were most interested in acquiring were sewing and child care (cited by $41 \%$ and $25 \%$ of MAGs in Assiut), while MAGs in Souhag were more interested in learning how to read and write followed by sewing (45\% and $40 \%$, respectively).

The majority of those who expressed interest recommended a frequency of once or twice a week $(79.2 \%$ in Assiut and $83.6 \%$ in Souhag) and suggested that classes meet in the afternoon (63.7\% in Assiut and 67.2\% in Souhag). The preferred location for the classes was at the home of one of the participants, followed by a community development association. On the husband's potential approval of participation in such classes, nearly half of MAGs stated that their husband would approve (49.1\% in Assiut and $46 \%$ in Souhag). 


\section{CONCLUSION AND RECOMMENDATIONS}

The present study has a number of limitations. First, the sample was not randomly selected due to restrictions on accessing MAGs within households, thus interviewed MAGs may not be representative of all MAGs in rural Assiut and Souhag. Very young MAGS or those exposed to more serious problems may have been hidden by heads of households. Also, the fact that the interview was conducted in a household setting where auditory privacy may not have been fully guaranteed may have deterred some MAGs from revealing other problems that they may have been facing. Additional quantitative studies with more innovative data-collection methods are therefore recommended.

However, the present study has confirmed results of previous research that showed that early marriage is associated with increased social, economic, and health vulnerability for adolescent girls. MAGs in rural Assiut and Souhag have limited social networks, do not have much decision-making power, and their mobility is highly constrained. Economically, those MAGs are almost entirely dependent on their husbands as the great majority do not work for cash or have their own savings account. Moreover, they are vulnerable to a number of health risks such as early and repeated pregnancy, reproductive tract infections, sexual problems, and gender-based violence. Their access to reproductive health information is very limited and hence their knowledge level is low. Their health vulnerability is further compounded by their social and economic vulnerability, limited access to information, and constricted mobility. The illegal marriage status further limits MAGs' access to public services and exacerbates their vulnerability.

Despite the dire situation of MAGs in rural Assiut and Souhag, there are several windows of opportunity that could be capitalized on. First, a substantial percentage of these girls have completed basic or secondary education and hence could be easily reached with print material and/ or livelihood programs. Also, about half of MAGs have their own cell phones and hence could be reached directly by health care providers. The duration of the engagement period is fairly long (almost one year) which could be used to prepare the girls and their prospective husbands for their new life. Finally, there is a large network of primary health care facilities that is available in almost every village in
Egypt that could address the health needs of these women if health care providers are made aware of those needs and learn the necessary skills to address them.

\section{Following is a list of policy and program recommen- dations that could empower married adolescent girls, address their health needs, and ultimately eliminate child marriage:}

- Primary health care services should address the needs of MAGs, as the former are present in almost every village and neighborhood. Health care providers should be trained in identifying MAGs and in addressing their sexual and reproductive health $(\mathrm{SRH})$ needs. The former should screen MAGs for gender-based violence and should refer identified cases to designated facilities for legal and/or emotional support. Premarital counseling should be made an integral component of premarital health services and the scope of the discussion should be expanded to include topics such as sexual relations, wedding night, child rearing, FP, and husband-wife communication. Raedat Rifyat could play a key role in identifying MAGs, reaching out to them, educating them about SRH, and encouraging them to visit the health facility, as the former usually come from the same community and hence could be trusted by MAGs and their families. Administrative barriers that may prevent married adolescent girls from accessing public health services should be abolished (e.g., asking young women to show their marriage certificate or their husband's ID as a prerequisite for receiving reproductive health services).

- Social and economic factors that may exacerbate MAGs' SRH vulnerability should be addressed through asset-building programs. MAGs in rural Upper Egypt are very hard to reach as they are likely to be out of school and their mobility is limited. Programs are needed that provide "safe spaces" to those women, increase their social capital, and build their health, social, and economic assets. The Ishraq program, which offered literacy, sports, and life-skills training to out-ofschool adolescent girls in rural Upper Egypt, could be adapted to address the needs of married adolescent girls. Likewise, Meseret Hiwot provided married female adolescents in rural Ethiopia with HIV-related knowledge, skills, and social assets. Evaluation of the latter program showed that participants were more likely 
to report that their husbands helped with domestic work, their husbands accompanied them to the clinic, that they used FP and received voluntary counseling and testing for HIV (Erulkar, Lamesgin, and Muthengi 2010). Local NGOs in Egypt could play a key role in implementing similar programs for married adolescent girls, programs that are administered by young women from the same community.

- Community-awareness activities should educate male partners about the benefits of birth spacing and FP, rectify religious misconceptions about gender-based violence, and encourage husband-wife communication. Religious leaders could play a key role as their word is highly credible, especially in rural areas.

- Multifaceted interventions should be adopted to stop early marriage. Girls should be encouraged to stay in school through various mechanisms (e.g., school supplies or uniforms for girls, conditional economic incentives for parents who keep their daughters in school and unmarried). The current law should be enforced and should be amended to include punishing both the mazoon and the girl's parents for issuing a marriage contract even if it is not registered. Livelihood opportunities should be made available to young women in rural Upper Egypt to enhance their status within their families and to alleviate their families from the burden of feeding them. Finally, sociocultural norms that condone early marriage should be addressed through mass media, community conversations, and educational and religious institutions. 


\section{REFERENCES}

Amin, S. 2011. "Programs to address child marriage: Framing the problem." Promoting healthy, safe, and productive transitions to adulthood. Brief no. 14. Updated January 2011. www.popcouncil.org/uploads/pdfs/

TABriefs/14_ChildMarriage.pdf.

Brady, Martha, Ragui Assaad, Barbara Ibrahim, Abeer Salem, and Rania Salem. 2007. "Providing New Opportunities to Adolescent Girls in Socially Conservative Settings: The Ishraq Program in Rural Upper Egypt." New York: Population Council.

Bruce, J. 2003. "Overview and Reflections of Child Marriage and Adolescent Policy." Washington, DC, USA: ICRW.

Central Agency for Public Mobilization and Statistics (CAPMAS). 2014. Household Income and Expenditure Survey 2012/2013. Cairo, Egypt: CAPMAS.

El-Mouelhy, M. 2013. KABP Base Line Survey. Basic Life Options for Girls: Addressing Early Marriage in Egypt. Cairo: CARE.

Erulkar, A. 2013. "Very early marriage, marital relations and intimate partner violence in Ethiopia," International Perspectives on Sexual and Reproductive Health 39(1): 6-13.

Erulkar, A., A. Lamesgin, and E.N. Muthengi. 2010.

“'Meserete Hiwot' (Base of Life): Supporting married adolescents with HIV prevention and reproductive health in rural Ethiopia." Population Council.

Erulkar, A. and Placide Tapsoba. 2015. "Building an evidence base to delay marriage in sub-Saharan Africa." www.popcouncil.org/research/building-an-evidence-base-to-delay-marriage-in-sub-saharan-africa.

Glynn, J.R. et al. 2001. "Why do young women have a much higher prevalence of HIV than young men? A study in Kisumu, Kenya and Ndola, Zambia," AIDS 15(Suppl. 4): S51-S60.

Hindin, M.J., S. Kishor, and D.L. Ansara. 2008. “Intimate Partner Violence among Couples in 10 DHS Countries: Predictors and Health Outcomes," Calverton, MD, USA: Macro International.

International Center for Research on Women (ICRW). 2005.

Development Initiative on Supporting Healthy

Adolescents (DISHA) Project. Washington, DC: ICRW.

Jensen, R. and R. Thornton. 2003. "Early female marriage in the developing world," Gender and Development 11(2): 9-19.
Mensch, B., J. Bruce, and M. Greene. 1998. The Uncharted Passage: Girls' Adolescence in the Developing World. New York: Population Council.

Ministry of Health and Population (MOHP), El-Zanaty and Associates [Egypt], and ICF International. 2015. Egypt Demographic and Health Survey 2014. Cairo, Egypt and Rockville, Maryland, USA: Ministry of Health and Population and ICF International.

Population Reference Bureau. PRB. 2011. "Fact Sheet on Child Marriage." www.prb.org/Publications/

Media-Guides/2011/child-marriage-fact-sheet.aspx.

Roushdy, R. and M. Sieverding (eds). 2015. Panel Survey of Young People in Egypt (SYPE) 2014. Generating Evidence for policy, programs and research. Cairo: Population Council.

Santhya, K.G., U. Ram, R. Acharya, and S.J. Jejeebhoy. 2010. "Associations between early marriage and young women's marital and reproductive health outcomes: Evidence from India," International Perspectives on Sexual and Reproductive Health 36(3): 132-139.

Speizer, I.S. and E. Pearson. 2011. "Association between early marriage and intimate partner violence in India: A focus on youth from Bihar and Rajasthan," Journal of Interpersonal Violence 26(10): 1963-1981.

UNICEF. 2001. “Early Marriage: Child Spouses." Florence: UNICEF Innocenti Research Centre.

2011. "State of the World's Children 2011: Adolescence, an Age of Opportunity." New York: UNICEF.

2017. "Child marriage is a violation of human rights, but is all too common." https://data.unicef.org/topic/ child-protection/child-marriage/. Accessed 6 March 2017.

United Nations (UN). 1995. "International Conference on Population and Development, Cairo 5-13 September, 1994. Programme of Action." New York: United Nations, Department for Economic and Social Information and Policy Analysis.

United Nations Development Program (UNDP). 2010. “Egypt's Progress Towards Achieving the Millennium Development Goals."

United States Agency for International Development (USAID). 2009. Preventing Child Marriage: Protecting Girls Health." Issue Brief. Washington, DC: USAID. 

